\title{
Uleritema ofriógenes como entidad asociada al síndrome 18p- en un paciente pediátrico
}

\author{
Ulerythema ophryogenes as an entity associated with $18 p$ - syndrome in a \\ pediatric patient
}

\author{
Dra. Carmen Couselo-Rodríguez ${ }^{a, b}$, Dra. Ana Batalla-Cebey ${ }^{a, b}$, Dr. Carlos Álvarez-Álvarez ${ }^{b, c}$ y \\ Dra. Ángeles Flórez $z^{a, b}$
}

\section{RESUMEN}

El uleritema ofriógenes es un trastorno cutáneo benigno y poco frecuente que se presenta habitualmente en la infancia. Se caracteriza por pápulas foliculares eritematosas y queratósicas en el lateral de las cejas, que con el tiempo suelen evolucionar a alopecia cicatricial. Dicha entidad puede aparecer como manifestación clínica aislada o asociada a varios síndromes congénitos (18p-, Cornelia de Lange, Noonan y RubinsteinTaybi, entre otros).

Presentamos el caso de un paciente de 13 años con síndrome $18 \mathrm{p}$ - que consultó por lesiones puntiformes rugosas al tacto y pérdida de pelo en ambas cejas (uleritema ofriógenes), así como por hiperqueratosis pilar en brazos. Esta tríada, conocida como síndrome de Zouboulis, ha sido poco descrita en la literatura. Se considera que el reconocimiento del uleritema ofriógenes es de crucial importancia ya que, ante su presencia, debería realizarse una anamnesis y una exploración física exhaustivas en búsqueda de otras alteraciones que pudieran orientar a la existencia de un trastorno genético subyacente.

Palabras clave: uleritema ofriógenes, queratosis, genética.

\section{ABSTRACT}

Ulerythema ophryogenes is a benign and rare skin disorder commonly presenting in childhood. It is characterized by erythematous and keratotic follicular papules located on the side of the eyebrows, and which over time tends to evolve into scarred alopecia. This entity may appear as an isolated clinical manifestation or associated with several congenital syndromes (18p-, Cornelia de Lange, Noonan, RubinsteinTaybi, among others).

a. Servicio de Dermatología del Complejo Hospitalario Universitario de Pontevedra, Pontevedra, España.

b. Grupo de Investigación Dermatología Inflamatoria, Pediátrica y Oncológica (DIPO), Instituto de Investigación Sanitaria Galicia Sur, Servizo Galego de Saude (SERGAS)-Universidad de Vigo (UVIGO).

c. Servicio de Anatomía Patológica del Complejo Hospitalario Universitario de Pontevedra, Pontevedra, España.

\section{Correspondencia:}

Dra. Carmen Couselo-Rodríguez:

carmen.couselo.rodriguez@sergas.es

Financiamiento: Ninguno.

Conflicto de intereses: Ninguno que declarar.
We present a 13-year-old male with 18p-syndrome who consults for rough lesions and hair loss in both eyebrows (ulerythema ophryogenes), as well as for hyperkeatosis pilaris in both arms. This triad, known as Zouboulis syndrome, has been rarely reported in the literature. We consider that the recognition of ulerythema ophryogenes is of crucial importance since, in view of its presence, comprehensive anamnesis and physical examination should be performed in search of other alterations that could guide the existence of an underlying genetic disorder. Key words: ulerythema ophryogenes, keratosis, genetics.

http: / / dx.doi.org/10.5546/aap.2021.e636

Cómo citar: Couselo-Rodríguez C, Batalla-Cebey A, Álvarez-Álvarez C, Flórez Á. Uleritema ofriógenes como entidad asociada al síndrome 18pen un paciente pediátrico. Arch Argent Pediatr 2021;119(6):e636-e638.

\section{INTRODUCCIÓN}

El uleritema ofriógenes, también llamado queratosis folicular atrófica facial, es un trastorno cutáneo benigno y poco frecuente que se presenta habitualmente en la infancia. Se caracteriza por pápulas foliculares queratósicas y eritematosas que se asientan preferentemente en el lateral de las cejas y que, con el paso del tiempo, pueden evolucionar a alopecia cicatricial. En ocasiones, se observan hallazgos similares en las mejillas y en la frente. ${ }^{1}$

Dicha entidad puede aparecer como una manifestación clínica aislada, asociada a otros trastornos de la queratinización folicular englobados dentro del término queratosis pilares, o presentarse junto con varios síndromes congénitos (síndrome de Cornelia de Lange, síndrome de Noonan, síndrome de RubinsteinTaybi, síndrome cardiofaciocutáneo y síndrome $18 \mathrm{p}$-, entre otros). $)^{2,3}$

Se describe el caso de un paciente con deleción en el brazo corto del cromosoma 18 (síndrome $18 \mathrm{p}-$ ), en el que se observó uleritema ofriógenes e hiperqueratosis pilar. 


\section{CASO CLÍNICO}

Varón de 13 años con síndrome $18 \mathrm{p}$ (deleción 18p11.1), retraso general del desarrollo psicomotor, déficit de IgA, dermatitis atópica y artritis idiopática juvenil en tratamiento con metotrexato y etanercept.

Acudió a la consulta por lesiones puntiformes rugosas al tacto y pérdida de pelo en ambas cejas de ocho meses de evolución.

En la exploración física se observaron pápulas foliculares hiperqueratósicas y eritematosas en ambas cejas, con alopecia parcheada (Figura 1a). Además, existían lesiones similares en ambas mejillas, así como pápulas foliculares hiperqueratósicas rodeadas de un halo eritematoso en cara externa de brazos y muslos, y carentes de eritema perilesional en tronco (hiperqueratosis pilar) (Figura 1b).

El estudio histológico del área afectada de la ceja mostró alopecia cicatricial sin datos de inflamación, compatible con uleritema ofriógenes (Figura 2).

FIgURA 1. A: alopecia parcheada en la ceja, con pápulas foliculares queratósicas. B: hiperqueratosis pilar en el tronco

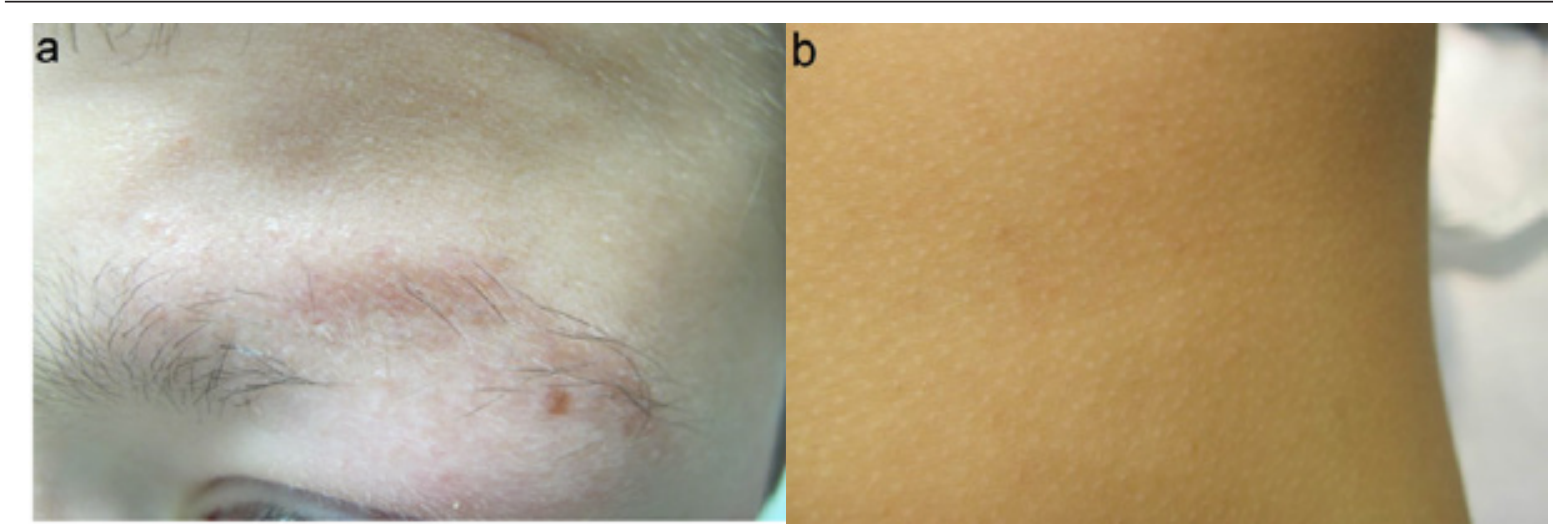

FIGURA 2. Dermis con sustitución de folículos pilosebáceos por cicatrices estrelladas (flecha), sin evidencia de inflamación (tinción con hematoxilina y eosina, $40 x$ )

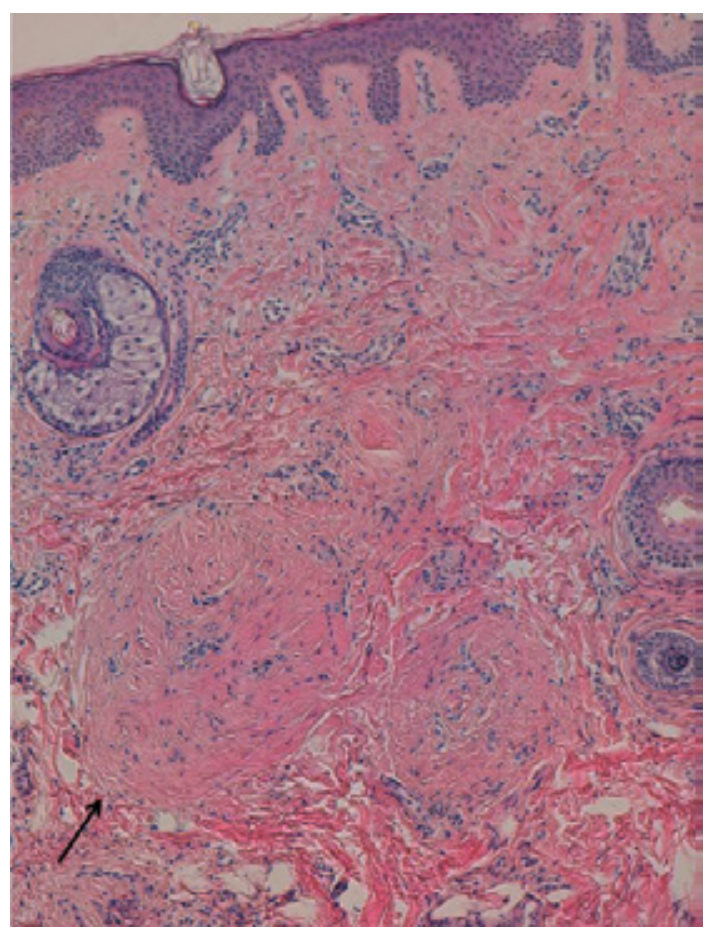


Se indicó una aplicación diaria de crema con urea al $10 \%$ durante 3 semanas, y se observó una modesta mejoría. Actualmente, el paciente se encuentra en seguimiento con controles anuales.

\section{DISCUSIÓN}

La monosomía del cromosoma 18p, o síndrome $18 \mathrm{p}-$-, es un trastorno que resulta tras la deleción completa o parcial del brazo corto del cromosoma 18, con una incidencia estimada de 1 entre 50000 recién nacidos vivos. Aunque las manifestaciones clínicas pueden variar entre pacientes, este síndrome suele cursar con retraso global del desarrollo, talla baja y dismorfismos craneofaciales (puente nasal plano, micrognatia, ptosis palpebral y orejas prominentes, entre otros). ${ }^{4}$

Se ha descrito la asociación del síndrome $18 \mathrm{p}$ - con queratosis pilar y uleritema ofriógenes. Hasta la fecha esta tríada ha sido escasamente reportada, y en 2014 Liakou et al. propusieron denominarla síndrome de Zouboulis en honor a quien la describió por primera vez. ${ }^{5}$

El hallazgo de esta asociación sugiere que los genes responsables de la queratinización folicular podrían estar localizados en el brazo corto del cromosoma 18. Zouboulis et al., consideraron como posible factor genético implicado la pérdida de expresión de $L A M A 1$, situado en la posición 18p11.3. ${ }^{6}$ Sin embargo, otros autores han propuesto la deleción del cromosoma $12 \mathrm{q}$ o la mutación de SOS1 (cromosoma 2p22.1) como posibles causas de los trastornos de la queratinización. ${ }^{7.8}$

En cuanto al tratamiento del uleritema ofriógenes, la utilización de queratolíticos y corticoides tópicos ofrece una mejoría parcial. No obstante, esta entidad tiende a mejorar de manera espontánea con el paso de los años. Más recientemente, se han informado efectos beneficiosos, sobre todo con respecto al eritema, con el láser de colorante pulsado y con la luz pulsada intensa. Cuando la alopecia cicatricial ya está instaurada, el trasplante de pelo en las cejas también sería una opción terapéutica para valorar. $^{2}$

El reconocimiento del uleritema ofriógenes es de crucial importancia ya que puede ser una entidad asociada a varios síndromes congénitos. Así, ante la presencia de este hallazgo, deben realizarse una anamnesis y una exploración física exhaustivas en búsqueda de otras alteraciones que pudieran orientar a la presencia de un trastorno subyacente. Esto posibilitaría un diagnóstico más precoz y, en consecuencia, un abordaje más temprano del cuadro sindrómico concomitante.

\section{REFERENCIAS}

1. De Sousa VC, Pinheiro R, Cunha N, Lencastre A, Cabete J. And next... Adnexa:Ulerythema ophryogenes and keratosis pilaris. Eur J Dermatol. 2018; 28(4):566-7.

2. Morton CM, Bhate C, Janniger CK, Schwartz RA. Ulerythema ophryogenes: updates and insights. Cutis. 2014; 93(2):83-7.

3. Flórez A, Fernández-Redondo V, Toribio J. Ulerythema ophryogenes in Cornelia de Lange syndrome. Pediatr Dermatol. 2002; 19(1):42-5.

4. Carvalho CA, de Carvalho AVE, Kiss A, Paskulin G, Götze FM. Keratosis pilaris and ulerythema ophryogenes in a woman with monosomy of the short arm of chromosome 18. An Bras Dermatol. 2011; 86(4 Suppl 1):S42-5.

5. Liakou AI, de Carvalho AVE, Nazarenko LP. Trias of keratosis pilaris, ulerythema ophryogenes and $18 \mathrm{p}$ monosomy: Zouboulis syndrome. J Dermatol. 2014; 41(5):371-6.

6. Zouboulis CC, Stratakis CA, Gollnick HP, Orfanos CE. Keratosis pilaris/ulerythema ophryogenes and $18 p$ deletion: is it possible that the LAMA1 gene is involved? J Med Genet. 2001; 38(2):127-8.

7. Klein OD, Cotter PD, Schmidt AM, BickDP, et al. Interstitial deletion of chromosome 12q: genotype-phenotype correlation of two patients utilizing array comparative genomichybridization. Am J Med Genet A. 2005; 138(4):34954.

8. Li K, Thomas MA, Haber RM. Ulerythema ophryogenes, a rarely reported cutaneous manifestation of noonan syndrome: case report and review of the literature. J Cutan Med Surg. 2013; 17(3):212-8. 